\title{
Effect of Ovsynch Protocol and Mineral Supplementation on Fertility in Pubertal and Peripubertal Buffalo Heifers
}

\author{
Ravikumar Kaliannan*, Selvaraju Mani and Prakash Subramaniyan \\ Department of Veterinary Gynaecology and Obstetrics, Veterinary College and Research \\ Institute, Namakkal -637 001, TANUVAS, Tamil Nadu, India \\ *Corresponding author
}

\section{A B S T R A C T}

Keywords

Ovsynch, Pubertal, Peripubertal, Buffalo heifers

Article Info

Accepted:

14 December 2017

Available Online:

10 January 2018
Forty pubertal and peripubertal buffalo heifers divided into four groups. Groups I and III were supplemented with mineral mixture. Group II and III were treated with Ovsynch protocol consisted of $10 \mu$ gi.m. injection of $\mathrm{GnRH}$ on the day of start (d 0), $500 \mu \mathrm{g}$ i.m. injection of $\mathrm{PGF}_{2} \alpha$ seven days later ( $\mathrm{d} 7$ ), another $10 \mu$ gi.m. injection of GnRH $48 \mathrm{~h}$ after $\mathrm{PGF}_{2} \alpha(\mathrm{d} 9)$ and AI 16 to $18 \mathrm{~h}$ after second GnRH injection (d 10). Group IV was control. The ovulatory response and conception rates were 50.00 and 20.00; 60.00 and 30.00; 90.00 and 40.00 and 100.00 and 20.00 per cent in Group I to IV, respectively. It conclude that ovsynch protocol and mineral supplementation improved conception rate in pubertal and peripubertal buffalo heifers.

\section{Introduction}

Buffalo usually attain puberty can be highly variable, ranging from 18 to 46 months.

The delay in puberty, consequently delays conception and results in low reproductive efficiency and lengthening of the nonproductive life. Synchronization of estrus has been helpful in solving of these problems in buffalo heifers. Pursley et al., (1995) reported that when estrus was synchronized with $\mathrm{GnRH}-\mathrm{PGF}_{2} \alpha$ - GnRH protocol, ovulation occurred within $18 \mathrm{~h}$ period in all the treated animals. Although much work has been done using ovsynch in synchronization of ovulation in cattle, information on their use in buffaloes especially in peripubertal and pubertal buffalo heifers is limited. Hence the present study was taken up

To study the efficacy of mineral supplementation on estrus induction and conception rates in peripubertal and pubertal buffalo heifers.

To study the efficacy of Ovsynch protocol with or without mineral supplementation on estrus induction and conception rates in peripubertal and pubertal buffalo heifers. 


\section{Materials and Methods}

Forty healthy graded Murrahpubertal and peripubertal buffalo heifers aged between 2 and 4 years were selected after thorough gynaeco-clinical examination and ultrasound examination of ovaries. Buffalo heifers were dewormed orally with combination of Albendazole $(7.5 \mathrm{mg} / \mathrm{kg}$ body weight $)$ and Ivermectin $(200 \mu \mathrm{g} / \mathrm{kg}$ body weight $)$ bolus. Then randomly and equally divided into four experimental groups viz., Group I to III (Treatment groups) and Group IV (Control group). Groups I and III buffalo heifers given mineral mixture bolus orally at the dose rate of one bolus per day per buffalo for 10 days from the day of selection. The constituents of bolus of mineral mixture includes Copper -1.4 $\mathrm{gm}$, Cobalt $-0.1112 \mathrm{gm}$, Iodine- $014 \mathrm{gm}$, Iron - 1.4 gm, Manganese.56 gm, Selenium 0.006 gm, Zinc-0.56 gm, Vitamin E -0.05 gm, live Live Yeast - q.s., respectively. Buffalo heifers of Group II and III were treated with Ovsynch protocol consisted of intramuscular injections of $10 \mu \mathrm{g}$ of $\mathrm{GnRH}(2.5 \mathrm{ml}$, Buserelin acetate, Ovulanta $^{\circledR}$, Vet Mankind, New Delhi, India) on the day of start of synchronization of ovulation (d 0), $500 \mu \mathrm{g}$ of $\mathrm{PGF}_{2} \alpha$ ( $2 \mathrm{ml}$, Cloprostenol, Pragma ${ }^{\circledR}$, INTAS Pharmaceuticals, Ahmedabad, India) seven days later (d 7) and another $10 \mu \mathrm{g}$ of $\mathrm{GnRH}$ $\left(2^{\text {nd }} \mathrm{GnRH}\right) 48$ hours after the $\mathrm{PGF}_{2} \alpha$ (d 9) and Timed Artificial Insemination (TAI) at 16 to 18 hours after the second GnRH injection (d 10) as described by (Pursley et al., 1995). In groupI and IV buffalo heifers Artificial Insemination was done during the observed estrus. The groups II and III buffalo heifers were closely observed for estrus signs during the period of treatment and during the $66 \mathrm{~h}$ after $\mathrm{PGF}_{2} \alpha$ administration. Buffalo heifers in the group I was observed for signs of estrus for 30 days from the completion of mineral mixture supplementation. Estrus response in percentage was calculated as number of animals expressed estrus divided by number of animals treated in each group and multiplied by 100 . Onset of estrus was calculated in hours, from the time of $\mathrm{PGF}_{2} \alpha$ administration to the time of first appearance of estrus signs in group II and III, whereas in group I, the onset of the estrus was recorded from the time of completion of mineral mixture supplementation to the first appearance of estrus signs. The intensity of estrus was studied using behavioral changes, physiological changes and gynaecological observations and it was scored as described by (Rao and Rao, 1981) with slight modifications. Ovulatory response was assessed by rectal examination and ultrasonography at 10 days after induced estrus in groups II and III and observed estrus in group I and IV. Conception rate was calculated as number of buffalo heifers conceived to TAI at induced estrus in groups II and III and at observed estrus in group I and IV divided by number of animals treated in each experimental group and multiplied by 100 and it was expressed in percentage. Pregnancy was confirmed by rectal palpation and ultra sound scanning at 60 days post insemination.

\section{Results and Discussion}

All the pubertal and peripubertal buffalo heifers belong to ovsynch, ovsynch plus mineral mixture and control groups exhibited 100 per cent estrus. Similar finding was reported by (Velladurai et al., 2015) in crossbred cows and (Biradar et al., 2014) in repeat breeder buffaloes following Ovsynch treatment. Mineral mixture supplementation in group I buffalo heifers in this study showed 50 per cent estrus response and (Velladurai $e t$ al., 2015) observed 62.50 per cent estrus response in mineral supplemented postpartum cross bred cows. This might be due tofollicle size more than $10 \mathrm{~mm}$ at the time of $\mathrm{AI}$ in buffalo heifers as described by (Atanasov et al., 2011) in Bulgarian Murrah buffaloes. 
In the present study the overall mean time taken for the onset of estrus was 129.6 \pm 55.56 , $45.1 \pm 0.89$ and $42.8 \pm 0.61 \mathrm{~h}$ in mineral mixture, ovsynch and ovsynch plus mineral mixture groups, respectively. There was nonsignificant difference with regards to onset of estrus among ovsynch and ovsynch plus mineral mixture groups. (Ravikumar et al., 2007) reported that the interval to onset of estrus afterPGF $\mathrm{F}_{2} \alpha$ was48.8 \pm 7.74 and52.67 \pm $4.18 \mathrm{~h}$ in ovsynch-subestrus and ovsynch anestrus treated postpartum buffaloes and in crossbred cows, it was $49.04 \pm 3.17 \mathrm{~h} \mathrm{(3)}$.

The mean $( \pm \mathrm{SE})$ duration of induced estrus in mineral mixture, ovsynch and ovsynch plus mineral mixture groups and control group were $26.8 \pm 1.59,23.7 \pm 1.27,26.3 \pm 0.72$ and $27.3 \pm 1.18$ hours, respectively. These findings were in concurrence with the reports of (Ravikumar et al., 2007) in buffaloes and (Velladurai et al., 2015) in cows.

The number and percentages of pubertal and peripubertal buffalo heifers showed intense, intermediate and weak estrus intensities were 4 (40.00), 1(10.00) and 0(0); 2 (20.00), 6 (60.00) and 2 (20.00); 5 (50.00), 4 (40.00) and 1 (10.00) and 5 (50.00), $5(50.00)$ and $0(0)$, in mineral mixture, ovsynch, ovsynch plus mineral mixture groups and control group, respectively.In this investigation, mineral mixture supplementation in ovsynchtreated buffalo heifers (group III) resulted in higher estrus expression rates in pubertal and peripubertal buffalo heifers. Minerals act as co-enzymes for the production of reproductive hormones especially in steroidogenesis (Pandey et al., 2007). Calcium plays a vital role in steroidogenesis by influencing delivery or utilization of cholesterol by mitochondria or by stimulating the conversion of pregnenolone to progesterone. $\mathrm{GnRH}$ stimulation of the pituitary gland to increase LH secretion involved calcium dependent mechanism
(Hurley and Doane, 1989). Even marginal deficiency of phosphorus was sufficient to cause disturbances in pituitary-ovarian axis without manifesting deficiency syndrome (Arosh et al., 1998). These reasons might explain the increased rate of intense estrus intensity in mineral mixture treated pubertal and peripubertal buffalo heifers.

The percentages of ovulatory response following day 10 post $\mathrm{AI}$ in pubertal and peripubertal buffalo heifers were 50.00, 60.00, 90.00 and 100.00 per cent, in mineral mixture, ovsynch, ovsynch plus mineral mixture and control group, respectively. (Velladurai et al., 2015) observed similar ovulatory response in mineral mixture treated (50 per cent) and ovsynch plus mineral mixture (100 per cent) treated postpartum cross bred cows. (Ravikumar et al., 2007) recorded 83.33 and 54.54 per cent ovulatory response in ovsynch treated postpartum subestrus and anestrus buffaloes, respectively. 72 per cent ovulatory response was observed by (Hoque et al., 2014) in postpartum cyclical buffaloes in ovsynch treatment. The reduced ovulatory response observed in mineral mixture group (50.00 percent) could be due to the sequelae of suppressed hypothalamic GnRH and pituitary LH secretion which depressed the ovarian function and in ovsynch treatment for getting good ovulatory response it requires suitable follicular development at the time of initiation of ovsynch and prevention of premature luteolysis (Pursley et al., 1997). This result clearly proved that mineral mixture supplementation definitely improved the ovulation rates in pubertal and peripubertal buffalo heifers when they were combined with Ovsynch program in buffalo heifers. The percentages of conception rate in pubertal and peripubertal buffalo heifers were $20.00,30.00,40.00$ and 20 per cent, in mineral mixture, ovsynch, ovsynch plus mineral mixture and control group, respectively. (Velladurai et al., 2015) 
observed 37.50 and 25.00 per cent first service conception in mineral mixture and ovsynch plus mineral mixture treated postpartum RFM affected crossbred cows. Similar conception rate were reported by Ravikumar et al., (2007) 33.33 per cent and Hoque et al., (2014) 28 per cent in postpartum cyclic buffaloes treated with ovsynch protocol.

The results of the present study conclude that ovsynch protocol and mineral supplementation improved conception rate in pubertal and peripubertal buffalo heifers.

\section{References}

Arosh SKJ, Singh SK and Rajkumar R. Reproductive disorders and their management in cattle and buffalo: A review. Indian J. Anim. Sci., 1998; 75: 858-873.

Atanasov A, Yotov S, Antonov A and Kolev P. Induction of oestrus and conception rates in Bulgarian Murrah buffaloes after fixed-time artificial insemination (a preliminary study). Bulg. J. Vet. Med., 2011; 14(3):165-170.

Biradar S, Tandle MK, Haribabu Y, Usturge SM, Patil NA. and Suranagi MD. Study on efficacy of Cosynch and Ovsynch protocol on fertility in repeat breeder buffaloes. Indian J. Advan. Plant Res., 2014; 1(5):1-3.

Hoque MN, Talukder A, Akter $\mathrm{M}$ and Shamsuddin M. Evaluation of ovsynch protocols for timed artificial insemination in water buffaloes in Bangladesh. Turkish J. Vet. Anim. Sci., 2014; 38: 418-424.

Hurley WL and Doane RM. Recent developments in the roles of vitamins and minerals in reproduction. J. Dairy Sci., 1989; 72: 784-804.

Pandey AK, Shukla SP, Pandey SK and Sharma YK. Haemato-biochemical profile in relation to normal parturition buffaloes and buffaloes with retained fetal membranes. Buffalo Bull., 2007 26: 46-49.

Pursley JR, Kosorok MR. and Wilt bank MC. Reproductive management of lactating dairy cows using synchronization of ovulation. J. Dairy Sci., 1997; 80: 301306.

Pursley JR, Mee MO and Wilt bank MC. Synchronization of ovulation in dairy cows using $\mathrm{PGF}_{2} \alpha$ and GnRH. Theriogenology, 1995; 44: 915-923.

Rao SV and Rao AR. Oestrus behaviour and ovarian activity of crossbred heifers. Indian Vet. J., 1981; 58: 881-884.

Ravikumar K, Asokan SA and Veerapandian C. Effect of ovsynch protocol on fertility in postpartum subestrus and anestrus buffaloes. Tamil Nadu J. Vet. Anim. Sci., 2007; 3:205-208.

Velladurai C, Ezakial Napolean R, Selvaraju $\mathrm{M}$ and Doraisamy KA. Ovsynch Protocol for Improving Oestrus and Conception ratein Retained Fetal Membrane (RFM) Affected Cows. Intas Polivet, 2015; 16 (I): 59-61.

\section{How to cite this article:}

Ravikumar Kaliannan, Selvaraju Mani and Prakash Subramaniyan. 2018. Effect of Ovsynch Protocol and Mineral Supplementation on Fertility in Pubertal and Peripubertal Buffalo Heifers. Int.J.Curr.Microbiol.App.Sci. 7(01): 1940-1943. doi: https://doi.org/10.20546/ijcmas.2018.701.234 